\title{
"Clanes" en Tayikistán: Hacia una perspectiva antropológica
}

\section{Diana I báñez Tirado}

Master in Social Anthropology. School of Oriental and African Studies, University of London.

Profesor titular adscrita al Centro de Relaciones Internacionales de la Facultad de Ciencias Políticas y Sociales de la Universidad Nacional Autónoma de México.

221087@soas.ac.uk

\section{Resumen}

El presente artículo se centra en el estudio de las diversas formas de subjetividades contemporáneas, tanto individuales como colectivas en Tayikistán, las cuales sin embargo, han sido académicamente restringidas a ser denominadas como "relaciones clánicas". El artículo enfatiza que estas categorías son dinámicas, negociadas, y refutadas por la población local.

\section{Abstract}

This article focuses on the study of various forms of contemporary subjectivities, both individual and collective in Tajikistan, which however, have been academically restricted to be referred to as 'clan relations'. The article emphasizes that these categories are dynamic, negotiated, and contested by the local population.

Palabras Clave: Tayikistán, clanes, identidades, subjetividad, elites políticas

Keywords: Tayikistán, clans, identity, subjectivity, political elites

\section{I ntroducción ${ }^{1}$}

El viejo coche Lada de los años ochenta se detuvo por cuarta vez en unas horas en medio del camino que conduce al paso montañoso de Ayni: el motor se había calentado otra vez. Era una tarde de verano del 2005 cuando, en la ruta que conduce hacia el norte de Taykistan, mi amiga y yo presenciamos un corto y ordinario incidente que despertaría mi interés sobre los llamados 'clanes' en Tayikistán. Mientras esperábamos que nuestro conductor, Amir, trajera agua para enfriar el motor, un hombre con ropas raídas y sucias apareció junto a nuestro automóvil. El hombre venía bajando de la montaña tras cazar a una especie de tuza que colgaba de su hombro. Él y Amir nos explicaron que podíamos comprar el animal y cocinarlo para la cena, y así probar una nueva experiencia culinaria al tiempo que ayudábamos al pobre cazador y a su familia quienes necesitaban urgentemente algo de dinero. De pronto un auto Mercedes Benz nuevo se estacionó junto a nosotros; cuatro hombres vistiendo trajes sastres rayados y zapatos de punta se bajaron, jalaron violentamente el animal del hombro del cazador, nos miraron y dijeron algo en tayiko que no alcanzamos a comprender, lo que provocó grandes risotadas entre ellos. Acto seguido, uno de los hombres empujo al cazador quitándolo del camino y grito algunas palabras a nuestro chofer. Todos ellos subieron de nuevo a su vehículo, desapareciendo tan pronto como habían llegado, llevándose consigo (y sin pagar) la tuza que nos había sido ofrecida primero. Todo esto no paso en más de un minuto, y mi amiga y yo preguntamos qué 
pasaba. Amir amargamente dijo: ‘akh! Kulobis! Pashli vse na khui!”2. El pobre cazador regresó caminando hacia la montaña mostrando una clara impotencia en su mirada, y nosotros continuamos nuestro viaje en compañía de Amir, quien días más tarde trató, sin éxito, de conseguir vodka en el lago de Iskander Kul haciéndose pasar por un Kulobi.

Tayikistán atravesó por una guerra civil entre 1992 y 1997, en la cual el discurso de 'políticas clánicas' y 'conflicto entre clanes' fue usado en el país tanto por políticos como por periodistas, y a su vez fue extendido en la academia, especialmente en los trabajos de ciencia política. Las diferencias entre los 'clanes' y su relación con las estructuras de poder se mantienen presentes en la retorica de diferentes grupos en Tayikistán en diversos niveles de la economía y la política. Sin embargo, de acuerdo a algunos análisis académicos, las categorías referentes a los 'clanes' han sido usadas por elites políticas para movilizar a la población tayika, aunque se argumenta que la gente, a su vez, reflexiona, negocia, representa, interpreta y personifica las mismas categorías en diversos contextos de la vida cotidiana. Generalmente se acepta la existencia de cuatro 'clanes' principales en Tayikistán basados en divisiones territoriales y administrativas: Gharm, Khojand, Kulob y Pamir o Badakhshan. Actualmente la élite más poderosa en el gobierno proviene de Kulob. Por ejemplo, el presidente Emmomali Ralhmonov es originario del 'clan' Kulobi, y su lugar de nacimiento se ubica en Danghar originalmente habitado por Kulobis. Esta afirmación es expresada tanto por políticos como por gran parte de la población en general. En éste sentido, Collins (2006) afirma que 'clan' es generalmente entendido como una red social que incorpora a familias extendidas conectadas por relaciones de parentesco y clientelares, siendo el blat y el matrimonio arreglado dos de los mecanismos que perpetúan su existencia. ${ }^{3}$

Contrariamente a los trabajos académicos sobre Tayikistán que aceptan la existencia de los 'clanes' como colectividades sociales, grupos identitarios y élites políticas, el presente artículo tiene un enfoque diferente. Éste se centra en el estudio de las diversas formas de subjetividades contemporáneas, tanto individuales como colectivas en Tayikistán, las cuales sin embargo, han sido académicamente restringidas a ser denominadas como 'relaciones clánicas'. Mi argumento es que las relaciones sociales en el contexto tayico son más complicadas, paradójicas y multidimensionales, y por lo tanto no deberían ser abarcadas en su totalidad bajo modelos empiricistas de clasificación social que categorizan a una gran gama de procesos sociales, políticos y económicos, y formas de auto-representación e identidad como clanes, tribus, relaciones de parentesco y/o clientelares. Mi objetivo es fragmentar dichos colectivos enfatizando que el hecho de afirmar que estas categorías son dinámicas, negociadas, y refutadas por la población local, no es suficiente para salir de sus limitaciones analíticas que dejan de lado a las variadas y complejas gamas de subjetividades individuales y grupales que van más allá de ser simples identidades y lealtades "clánicas".

Primeramente, este trabajo revisa la literatura general sobre Asia Central y específicamente Tayikistán, y posteriormente se divide para el análisis en tres secciones que exploran las diferentes dimensiones en las cuales la gente en Tayikistán; a) interactúa y participa dentro del estado y con la formulación del nacionalismo tayico por medio de determinadas expresiones y personificaciones de las diferencias y las similitudes mutuamente constituidas b) se ubica a sí misma y a los otros en el espacio físico e imaginario en relación a su pertenencia al estado-nación, a una región interna específica y a diversas denominaciones colectivas c) reflexiona y entiende la multivocalidad al experimentar los espacios, las marcas de identidad, las 
transformaciones económicas en el contexto de ciertos procesos transnacionales. Éste artículo no solamente está enfocado a las especificidades de la experiencia humana, sino que también explora las diversas subjetividades en interacción con el contexto social tomando en cuenta movilidad y transformación.

\section{Revisión de literatura: zonas teóricas sobre Asia Central}

En esta sección discuto las diversas formas en las que los estudios regionales sobre Asia Central han sido conformados de acuerdo a determinadas tendencias temáticas (zonas de teoría) provenientes especialmente de la ciencia política. En este sentido surgen diversas preguntas acerca de las implicaciones generadas a partir de asumir a priori que Asia Central existe como una 'región cultural' bien delimitada. Siguiendo el debate de Abu Lughod (1989) sobre las 'zonas de teoría antropológica' para el Medio Oriente, a continuación exploro las tendencias que conforman las zonas teóricas para Asia Central y las fuerzas analíticas que limitan la distribución temática en la investigación sobre esta región. ${ }^{4}$ Además, analizo cómo las especificidades sociales, económicas y políticas en los procesos regionales has sido estudiadas con métodos y paradigmas que dan preeminencia a las estructuras abstractas de organización social y a las formas objetivadas de socialidad, mientras que dejan de lado a las diversas subjetividades como formas de experiencia cotidiana.

Desde finales del siglo XIX Srednaya Aziia (reconocida en la tradición académica rusa como Uzbekistán, Turkmenistán, Kirguistán, Tayikistán y a veces Kazajstán), fue una región fundamental para la etnografía soviética. Los etnógrafos rusos, comprometidos con las políticas administrativas coloniales, desarrollaron teorías y modelos que fueron posteriormente usados para conformar a las Repúblicas Socialistas de la Unión Soviética (URSS), así como para organizar sus fronteras internas en la década de los treintas. $^{5}$ Dichas repúblicas fueron caracterizadas por el surgimiento de un grupo 'nacional' mayoritario y diversas 'minorías', de acuerdo a supuestos patrones comunes de sociedades ya existentes, y a la posterior conformación de granjas colectivas en formas de kolkhoz y sovkhoz. En la academia euroamericana, Asia Central se convirtió en una importante 'región' después del colapso de la Unión Soviética en 1991.

Desde entonces, la literatura general sobre Asia Central ha sido dominada por estudios enfocados al análisis del estado en términos de "transición política" (Rumer 2005), "continuidad" de las élites en el poder y de los gobiernos autoritarios (Dudarev 2001; Gafarly \& Rass 2001; Botiakov 2003; Schatz 2002), “democratización" (Kovalskii 2001), "sociedad civil" (Holt 1999; Starr 1999; Freizer 2005; Megoran 2005), y nacionalismo y etnicidad (Atkin 1992; Gross 1992; Roy 2000; Abashin, 2006). La mayoría de los temas económicos se refieren a transformaciones tales como las reformas agrarias (Zhukov 2005), privatizaciones, "transición" a la economía de mercado (Uyanik \& Segni 2001; Volgina, Gafarly \& Semenova 2001; Trushin \& Trushin 2002; Zhukov 2002), y crisis y ayuda internacional. Recientemente se ha enfatizado el impacto de lo "local" en las prácticas políticas que perpetúan la continuidad de las formas nativas de producción, explotación y corrupción contextualizadas en variadas relaciones de poder (Wegerich 2006; Trevisani 2007; Ilkhamov 2007; Markowitz 2008). Con los nuevos acuerdos internacionales sobre la explotación y comercialización de petróleo y gas natural, particularmente en Kazajastán y Turkmenistán, la geopolítica y la seguridad regional se han convertido en una zona teórica, así como las relaciones internacionales de países de Asia Central con el mundo (Jonson \& Allison, 2001; Zviagel'skaia, 2005; Olcott 2005; Rumer 2007). De la misma manera, el Ilamado 'I slam político' y el "renacimiento" islámico ha sido una zona de teoría gracias a tendencias globales en la producción académica en general, y a determinados 
procesos políticos en el contexto regional. ${ }^{6}$ Durante y después de la guerra civil en Tayikistán y con el surgimiento de movimientos asociados al Talibán en Afganistán, los temas de "radicalismo" islámico han estado particularmente presentes tanto en los discursos políticos y periodísticos, como en la literatura académica. (Spolnikov 1994; Makhamov 1994; Malashenko 2001; Abdullaev 2002; Rashid 2002; Belokrenitsky 2005; Naumkin 2005). ${ }^{7}$ En resumen, la literatura general ha subrayado la "transición" como el aspecto central dentro del espectro de los estudios económicos, políticos e incluso religiosos. Ésta es una de las claves para comprender las tendencias en las zonas de teoría referentes no solamente a Asia Central, sino específicamente a Tayikistán: los académicos han explorado las causas de la guerra civil en Tayikistán, argumentando por que el estado "falló" en alcanzar una "transición" pacífica hacia la democracia y la liberalización económica. Otras cuestiones repetidamente analizadas se refieren a como diversos grupos (especialmente 'clanes') fueron polarizados y movilizados durante la guerra, y como los conflictos de intereses entre las élites clánicas "fragmentaron" al país (Atkin 1994; Dudoignon; 1994; Akbarzadeh 1996; Roy 2000; Kuzmin 2001; Nourzhanov 2005). En consecuencia, el tropo del estado también se ubica en el centro de la producción académica acerca de los "clanes" en Tayikistán, así como las aproximaciones que concentran su atención hacia colectividades y grupos. La dominación de ambas tendencias, es la razón para el silencio de otros temas también importantes entre los cuales se ubican las diferentes experiencias cotidianas de los individuos y los grupos en el contexto de la vida diaria.

A su vez, existe otra tendencia teórica significativa en los estudios sobre Asia Central que tiene implicaciones para la priorización de estructuras y colectividades objetivadas, las cuales ignoran la agencia individual y las subjetividades. En general, la mayoría de la literatura intenta refutar ciertas "evidencias" producidas por la previa escuela etnográfica soviética que, basada en la epistemología marxista asumía que la etnogénesis y la formación de las naciones es un proceso natural localizado en una progresiva línea de evolución social (Petrova-Averkieva 1980). No obstante, los trabajos etnográficos de la escuela soviética continúan influenciando la producción académica mundial sobre Asia Central: el análisis de las sociedades de la region han sido dominadas por teorías referentes a la identidad, etnicidad y sus relaciones de exclusión e inclusión de las mismas en los nacientes estados-nacionales. Además, es común encontrar trabajos acerca de la formación histórica del estado, de la nación (o naciones) y de los 'grupos étnicos' (Centlivres \& Centlivres-Demont 1998; Jahangiri 1998; Ilkhamov 2004; Bergne 2007). Por una parte, cabe reconocer que los orígenes y la ubicación histórica de los procesos en cuestión son importantes, pero por otra, esta especie de "arqueología" del conocimiento ha limitado a las subjetividades personales como un objeto de estudio que no parecen significativos a pesar de constituir la base de la experiencia humana en sociedad. ${ }^{8}$ Dichas construcciones históricas tienden a trazar el origen de las poblaciones organizando y clasificando a las personas en colectividades conformando una especie de "geografía humana" y de "culturas" objetivadas (en este caso de los kazajos, uzbecos, kirguisos, tayicos, turkmenos y otros). ${ }^{9}$ La consecuencia es que:

"Los estudios acerca de la experiencia individual y las diversas formas de intersubjetividades y conciencia política son habitualmente reemplazados por el análisis de discursos y representaciones que generan imágenes sobresocializadas de la vida humana: ello tiende a enfatizar más la centralidad de la estructura social que la de la subjetividad". (Biehl, J., B. Good \& A. Kleinman 2007:13) 
Asimismo, el énfasis en las estructuras sociales es frecuentemente encontrado en los estudios sobre "clanes" en Tayikistán, siendo las redes sociales y las élites políticas el mayor centro de atención. A su vez, esto hace evidente el riesgo de sesgar el análisis al fundamentar las explicaciones en términos de "fallos" o "debilidades" en los procesos de consolidación del estado, de democratización y cambio a la economía de mercado. Es común asumir que el "estado fallido" o "débil" no funciona adecuadamente y ello coadyuva a la fractura de los proyectos de modernización económica y política, detiene el progreso y crea "fragmentación nacional" y luchas "clánicas/tribales". Estas conclusiones parciales han también oscurecido los diferentes niveles de experiencia individual y social tales como las innumerables formas en las que la gente interactúa con, y responde a las políticas y cambios económicos, y la diversidad multidimensional de expresión y ejecución verbal y física de las similitudes y diferencias por parte de los individuos al asumirse como tayicos, pamiris, khujandis o musulmanes shi' is o sunnis, o como una persona que vive en una familia mixta y que no se adecua a las grandes formaciones colectivas pre-establecidas. Con ello no niego la existencia de "clan" como una categoría de práctica con la cuál la gente interactúa en determinados contextos, ni tampoco que hay ciertos fenómenos en los cuáles "clan" como categoría de auto-representación colectiva aparece y se sobrepone con intereses de poder, control de recursos y, en general, un objetivo político compartido. Sin embargo "clan", como una categoría analítica y académica, no cubre la amplia y compleja variedad de procesos multidimensionales por medio de los cuales la gente en Tayikistán experimenta, expresa, representa y reflexiona su existencia individual, familiar y colectiva. ${ }^{10}$

\section{Teorizando los "clanes": de la representación objetiva hacia una aproximación antropológica subjetivista}

Las categorías referentes a colectividades sociales fueron usadas tanto en el contexto de la antropología euroamericana como en el de la soviética desde los inicios de la disciplina, especialmente para entender el funcionamiento de ciertos grupos en lo que se consideraban sociedades sin estado o estados en proceso de formación, centralización y modernización. ${ }^{11}$ Las teorías emergentes en este contexto relacionan el funcionamiento de tribus y clanes con diversos modos de linaje y de parentesco. Las características principales de estos modelos tribales y clánicos son a) que el grupo es una unidad con cierto grado de cohesión y lealtad a la autoridad local y b) que los miembros del grupo comparten patrones "culturales" y están ligados a un determinado territorio. De la misma forma se afirma que los individuos están relacionados mutuamente si no por parentesco, por un por sistema de adopción. ${ }^{12}$ En el caso de Tayikistán se ha sido reconocido que los "clanes" no son necesariamente grupos con relaciones de parentesco, ligados a un ancestro común, o que deban su cohesión a una lealtad basada en genealogía "real" (Collins 2006). Éstos no son ni siquiera similares a aquellos en Uzbekistán o Kirguistán, donde algunas de las denominadas "tribus" mantienen una narrativa de descendencia "imaginada" (Pétric 2002; Gullette 2007). La mayoría de los trabajos enfocados a los "clanes" en Tayikistán identifican ciertas relaciones sociales basadas en la pertenencia a un territorio administrativo como el factor más importante para la cohesión identitaria. De esta forma concluyen que "clan" es un grupo de familias extendidas habitando la misma región y que se puede transformar en grupos de ayuda mutua y de solidaridad. El "clan" está basado en previas formaciones del periodo soviético que fueron reforzadas gracias a la imposición del sistema colectivo de granjas: kolkhoz y sovkhoz (Chatterjee 2002). Asimismo, las relaciones interpersonales basadas en el "clan" como asociación de personas o como identidad son denominadas mahalgoroi o localismo, y la población tayica (especialmente los políticos) utilizan este vocabulario para auto-referirse a sí mismas y 
a sus alianzas políticas (Dudoignon 1994; Chatterjee 2002). Collins (2006) enfatiza la naturaleza política de los "clanes" y subraya su formación histórica. De esta forma, la tesis central gira alrededor de los objetivos políticos y de poder, y al deseo de controlar los recursos económicos por parte de la clase política, los tecnócratas y la inteligencia científica y literaria. De hecho, el proceso histórico de indigenización (korenizatsia) de los cuadros políticos tayicos en relación al centro de toda la URSS es acentuado para explicar las transformaciones y las estrategias políticas de los "clanes" (entendidos como élites) en su búsqueda por controlar el estado.

Antes de la independencia, la institución central del PC y de la economía nacional estaban controladas por una élite (denominada "clan") originada en Khojand; los cuadros medios de la KGB (Comité para la Seguridad del Estado) local eran ocupados por los Pamiris, y durante la perestroika los Kulobis comenzaron a dominar los cuerpos policiacos. La mayoría de los autores atribuyen el estallido de la guerra civil en 1992 a los intentos de cambiar éste sistema de cuotas de poder. Tras el conflicto, las relaciones "clánicas" han sido referidas por varios autores como "regionalismo", "localismo" o "faccionalismo". Inclusive, analíticamente los "clanes" se convirtieron también en grupos paralelos a las élites en forma de mafias y grupos paramilitares participando en actividades ilegales, ubicándose a los Kulobis y a los Pamiris como las principales redes asociadas con el tráfico de drogas (Dudoignon 1994; Kuzmin 2001; Chatterjee 2002). Otra dimensión que ha sido contenida en la categoría de "clan" es la formación "cultural", entendida como como grupos étnicos que comparte folclor y una identidad. De acuerdo a Kuzmin (2001) los "clanes" son etnias regionales que difieren entre sí por la diversidad de dialectos, rituales, costumbres y apariencia física general.

Tras analizar estas proposiciones teóricas se hace evidente que los "clanes" son representados como estrategias y partidos políticos (Collins 2006), alianzas regionales y locales (Chatterjee 2002), redes clientelares y de solidaridad (Dudoignon 1994; Collins 2006), mafias y grupos paramilitares (Kuzmin 2001; Chatterjee 2002), y etnias regionales (Kuzmin 2001). El problema de estas confusas y simplistas conceptualizaciones es que los "objetos" de estudio denominados "clanes" parecen ser colectividades humanas, relaciones sociales e incluso procesos.

Gullette (2007) elabora un análisis de las tribus en Kirguistán y explora cómo la categoría de "tribu" se manifiesta en las actividades cotidianas, por ejemplo durante los funerales. No obstante, su trabajo no explica cómo es que la gente reflexiona, representa y encarna las subjetividades individuales dentro del contexto colectivo. En contraste, existen algunos trabajos antropológicos sobre el sur de Asia que ilustran los complejos ángulos en los cuales los "clanes" en Tayikistán podrían ser analizados. Dichos estudios están enfocados a las subjetividades individuales y a las formas en que estas se hacen evidentes y se interrelacionan con colectividades politizadas (Michelutti 2008, Verkaaik 2004).

\section{Reconstituyendo la representación del estado y la nación y los “clanes"}

En esta sección analizaré las subjetividades individuales y colectivas en relación al estado-nación tayico y a otras dinámicas de relaciones de poder que van más allá de las supuestas lealtades "clánicas". Durante algunas décadas, la antropología sobre Medio Oriente y Asia Central ha desarrollado la misma gama de cuestionamientos acerca de tribus y clanes y su relación con el estado. En general, los académicos han teorizado como tribus y clanes se han convertido en formaciones políticas y sociales, hasta que punto éstas siguen los principios generales de parentesco, como dichos grupos se han integrado a los proyectos nacionales, y que clase de estrategias utilizan 
los líderes tribales para negociar con el estado, cuál es la relación de las tribus y clanes con los procesos de centralización y democratización, como sus líderes obtienen legitimidad y autoridad, así como acceso a recursos ya sea limitados u otorgados por el estado (Abu Lughod 1989; Gilsenan 1990; Caton 1990; Noelle-Karimi 1997; Varisco 2005). ${ }^{13}$ Por su parte, las teorías de "clanes" en Tayikistán conllevan concepciones estructuralistas sobre la relación del "estado" con los "clanes", siendo ambos conceptos basados en modelos objetivistas de complejas relaciones y subjetividades sociales. Los trabajos enfocados a los clanes como élites, se olvidan de estudiar las experiencias de la gente interesada en la política pero que simplemente interactúa con el "estado" através de las prácticas cotidianas en el contexto de la vida diaria. También se deja de lado a aquellos que participan en la política o que tienen intereses económicos y de poder pero que no expresan sus actividades en relación a la pertenencia a un "clan". En este sentido, el "estado" es comúnmente analizado como una institución o entidad separada de la sociedad, y su relación con los "clanes" está basada en imaginarios de un estado centralizado en proceso de democratización que lucha contra el faccionalismo o mahalgoroi. Otra suposición general es la binaria oposición del estado "moderno" con las practicas clánicas naturalizadas como más "tradicionales" (a veces incluso conceptualizadas como warlordismo), ${ }^{14}$ y las ideas del estado "fallido" frente al "exitoso" (democrático y moderno) (Akbarzadeh 1996; Nourzhanov 2005; Collins 2006; Schetter, Glassner \& Karokhail 2007). Finalmente, estos puntos de vista ignoran la importancia de la participación y compromiso de la gente con las políticas estatales en el contexto de la vida diaria porque se perciben como prácticas políticamente estériles y sin consecuencias (Eickelman 2002).

Por consiguiente, ara superar los problemas de representación objetivizada de los "clanes", es necesario reconstituir analíticamente al estado. Sneath (2007) propone entender al estado como una relación social en la cual la imagen de centralización como característica institucional no es preconcebida porque se concibe a las relaciones de poder en una forma horizontal, como en el histórico caso de la estepa de Mongolia, donde los poseedores del poder son localizados en una especie de aristocracia. Asimismo, Das y Poole (2004) analizan las cuestiones referentes a las prácticas sociales en los "márgenes" del estado conceptualizado más allá de las dicotomías de centro-periferia, público-privado, legal-ilegal. En la actividades de la vida cotidiana las personas no solamente resisten y cuestionan las prácticas regulatorias y disciplinarias del estado, sino que se interrelacionan con ellas en diversas formas por medio de las cuáles, el estado es constante y dialécticamente reconstituido. Además, lo que es considerado aun más importante para evitar falsas dicotomías es trazar la presencia del estado en la vida ordinaria, especialmente como éste es reflejado en las actividades diarias de la burocracia y la administración local (Herzfeld 1992; Gupta 2005). También se requiere "ir más lejos del discurso, de las categorías y de la perspectiva propia del estado y estudiar como éste aparece en formas localizadas de la cotidianidad: en resumen, estudiar al estado, o discursos del estado desde 'el campo'."(Hansen \& Stepputat 2001: 4).

Como ya se mencionó, la guerra civil en Tayikistán es uno de los temas más recurridos, siendo el imaginario principal el de los "clanes", bien delimitados, peleando entre sí por controlar los fragmentos del estado. Una de las conclusiones primarias es que la descomposición de las lealtades de la época soviética y la lucha por el poder llevaron a la fragmentación de la nación (Chatterjee 2002). No obstante, para poder seguir lógicamente el argumento sobre una supuesta "fragmentación", es necesario visualizar una nación tayica previamente unificada, así como a toda la gente sintiendo y rindiendo lealtad a su región de origen, a su "clan" y a su nación. Hasta ahora, ésta ha sido la retórica en el análisis de proyectos, discursos y élites en conflicto, pero se ha 
puesto poca atención a las formas en las que los pobladores de Tayikistán experimentaron la violencia y la movilización, así como el discurso de conflicto "clánico". En general, se ha dejado de lado el estudio de las experiencias vividas por las personas en la guerra civil y las diversas formas en las que ellas interpretan, analizan, imaginan, reflexionan y encarnan lo ocurrido en dichos eventos de violencia.

Antropológicamente, un campo más fértil para el análisis sería encontrar cómo los eventos de violencia penetran en lo ordinario y como la memoria de dichos sucesos se desdoblan en las recurrentes relaciones de la vida diaria (Das 2007). Marsden (en imprenta) ${ }^{15}$ explora cómo la guerra civil en Tayikistán afectó y continúa impactando las formas de experiencia cotidiana, y como ésta no es una especie de memoria colectiva sino una forma en la cual los individuos interactúan con el estado y la violencia por medio de su conciencia corpórea y existencia física. A través de cambios experimentados es su cuerpo, un hombre de Badakhshan afirma los efectos del conflicto en su propia auto-representación diciendo:

"Yo solía ser de otra manera...la guerra me hizo esto...antes de la guerra yo era un hombre fuerte, un boxeador, tú no podrías reconocerme en la era de los Soviets - nada de vodka ni cigarrillos nunca pasaron por mis labios... en aquel entonces."

El autor afirma que los efectos de la guerra son múltiples y tienen gran simbolismo en el entendimiento no solamente individual sino también colectivo en el contexto de la vida diaria: "desde la guerra civil muchos pamiris hablan del declive de la influencia política de su gente en la república". Es decir, que la auto-referencia a ser pamiri es solamente una parte de la experiencia y expresión del denominado "faccionalismo" dentro del estado tayico, misma que en sus términos, también es usada en la retórica presidencial para justificar ciertas políticas dirigidas al mantenimiento de la élite Kulobi actualmente en el poder controlada por el presidente. No obstante, Marsden (en imprenta) explora los detalles relativos a las formas en que los individuos experimentan e interactúan corporalmente las transformaciones dentro del estado. Esta postura desafía las suposiciones más generales acerca del autoritarismo y la continuidad de las viejas élites comunistas como especie de "survival" de épocas pasadas, enfatizando a su vez los constantes cambios políticos y de subjetivismo colectivo ubicados en el contexto de la vida diaria. Esto demuestra que no solamente las élites son las únicas implicadas en la política y la conformación del estado, y que la misma no es solamente perpetrada por relaciones clientelares o "clánicas", y finalmente que las "políticas clánicas" son sólo un aspecto de las expresiones oficiales, académicas y ordinarias acerca de lo ocurrido durante la guerra civil.

Más aún, existe otro fenómeno paralelo al localismo o mahalgoroi: el nacionalismo. En las últimas décadas en Tayikistán se ha desarrollado un proceso de conformación del estado, en el cuál, por medio de determinadas políticas culturales y administrativas se promociona la identidad tayica. En dicho discurso nacionalista los elementos persas de la población y la lengua tayica son enfatizados por medio de la promoción de ciertos tipos de música y de danza en los medios masivos de comunicación. Estos eventos, se dice oficialmente, son caracterizados por representar el orgullo y el folclor de la nación tayica. Sin embargo, Spinetti (2006) analiza la interacción de las diversas identidades regionales en Tayikistán a partir del estudio de diferentes tradiciones musicales locales, y explora cómo el proyecto nacional está relacionado a la ubicación y promoción de la música "auténtica" y "tradicional" del país (en la actualidad representada por la música del sur o Falak, y más específicamente por la música Kulobi), en oposición a lo que se reconoce como un "impuro" Shashmaqon. Este último 
se considera como un estilo originado en áreas uzbecas, y es percibido por algunos como música de Khojand. ${ }^{16}$ Davlat, el director del Ensable Falak afirma que el "Shashmoqon es totalmente uzbeco, turco...[en cambio] mi música es pura; yo no mezclo Shashmoqon... yo valoro la preeminencia de nuestro folclor...Falak es nuestra música nacional, el estilo de la gente que trabaja en la tierra"(2006:37,38). El Ensamble Falak está compuesto por aproximadamente 30 cantantes, músicos y bailarines, todos ellos seleccionados por medio de una competencia. La mayoría de ellos vienen la región de Kulob, pero también hay artistas de Balkh, Gharm, Varzob, Badakhshan y Zarafshon. Aunque es un hecho que las interpretaciones no están limitadas al género Falak, las características de las sociedades rurales del sur de Tayikistán son resaltadas; especialmente los registros Kulobis son el centro conceptual del proyecto. No obstante, los miembros del ensamble perciben en distinta forma las cuestiones artísticas y estéticas del proyecto, así como las relaciones de poder en las cuales el mismo se encuentra contextualizado. Por una parte algunos artistas hablan de la singularidad de sus interpretaciones como símbolos de su identidad regional. Pero por la otra, para algunos músicos, como Panjshambe Jurobov de Badakhshan, los ritmos y canciones Pamiris incluidas en el programa son, en realidad, interpretadas con una inflexión Kulobi que no corresponde al registro genuino de la música Pamiri. Este ejemplo demuestra como las representaciones culturales e históricas para conceptualizar la nación tayica funcionan como formas de "imaginar" a la nación (Anderson 1991), pero sobre todo, ilustra las maneras en las cuáles la gente interactúa con el proyecto nacional promovido por el gobierno, que en este caso da preeminencia a la promoción de valores estéticos Kulobis, además de que está en constante interacción con registros no tayicos.

Los proyectos nacionalistas tratan de definir a las diversas colectividades de acuerdo a ciertas clasificaciones de etnicidad, religión, género y lenguaje por medio de la ciudadanía (Kandiyoti 1994). Sin embargo, en Tayikistán este proceso se traslapa con otros en los cuáles el gobierno actual, comandado por autoridades Kulobis, busca controlar la posición oficial promoviendo lo que ellos mismos entienden como "cultura tayica". Por medio de ejemplos etnográficos es posible analizar como estos procesos tienen un efecto en lo que la población entiende como "la nación", y cómo la gente interactúa y representa diversas subjetividades en el proyecto nacional, cómo reflexiona sobre los valores estéticos y morales del mismo, y finalmente, cómo todo ello influye en la conformación de nuevas auto-referencias personales y colectivas que a primera vista parecen paradójicas.

De acuerdo a Marsden (en imprenta), los Pamiris enfatizan las diferencias entre el dialecto tayico culto y el popular, siendo el Kulobi uno de los menos refinados. Un hombre de Pamir expresa mientras ve en la televisión nacional a un presentador hablando en dialecto Kulobi:

“¿Qué va a ser de nuestro país cuando hay incluso profesores en la televisión que son incapaces de hablar tayico propiamente?".

Otro pamiri llamado Islam comenta sobre la agresividad de un policía kulobi: “Los Kulobis son unos perros...". Su amigo, también pamiri, le responde que él mismo lo ha escuchado hablando como si fuera kulobi, a lo que Islam reacciona diciendo:

“Toda esta gente alreador es kulobi...si no hablas como si fueras uno de ellos no te respetan". 
Marsden (en imprenta) explica como en Dushanbe la gente reflexiona acerca del surgimiento del dialecto kulobi como una lengua de poder, y cómo la promoción del "rudo" acento kulobi es enfatizado por los mismos kulobis. Sin embargo, en algunos casos la gente experimenta la "dominación" por medio de la activación de diversas estrategias para beneficiarse del poder por medio de la imitación del acento kulobi.

En relación a este tipo de fenómenos, Kroskrity (2000) afirma que las “ideologías de lenguaje" son las percepciones acerca de la lengua y el discurso, las cuáles son construidas por un interés específico de promoción de un determinado grupo social o cultural. De esta manera, el lenguaje se convierte en una práctica por medio de la cual ciertos grupos legitiman sus intereses. Lo que es aún más relevante en el ejemplo anterior, es que los kulobis no tratan de imponer sistemáticamente su dialecto a los otros, sino que más bien el uso de la lengua funciona en el contexto del "mercado lingüístico". ${ }^{17}$ Más aún, estos hechos no solamente se refieren a la gente usando concientemente el acento kulobi, sino también a ciertas formas de subjetividades relacionadas a nociones estéticas de refinamiento y humanidad. Marsden (en imprenta) afirma que:

“Estos dialectos tienen un significado mas profundo y constituyen formas más inmutables de distinción entre tayicos, algo habitualmente expresado...en términos del contraste entre lo humano (insaniyat) de algunos, y la animalidad (haiwaniyat) de otros".

Así, el estado-nación no solamente evidencia el proceso de certificación, administración y control por medio de prácticas burocráticas. El estado, imaginado simplistamente como una institución separada de la sociedad, tampoco es solamente la única fuente para definir lo étnico, lo regional, el género y las categorías morales que las personas negocian y refutan. Por el contrario, los pobladores de Tayikistán interactúan entre las categorías del estado-nación, y reflexionan, representan y personifican diversas y contrastantes formas de auto-entendimiento de las diferencias y las similitudes entre ellos. Finalmente, como Foster (1991) afirma, aunque el nacionalismo parece ser un fenómeno unitario, universal y moderno, éste gana considerable fuerza como una construcción de la realidad solamente cuando se interrelaciona con ontologías específicas sobre las cuáles la gente construye sus nociones de lo obvio, de lo asumido y de lo evidente.

\section{Subjetividades y la multivocalidad de la ubicación espacial}

En esta sección analizo las formas en las cuáles las denominaciones "clánicas" y de pertenencia a una determinada región territorial (funcionando como marcas de identidad) cambian en relación a la transformación en el espacio físico. A su vez, exploro ciertos aspectos de movilidad nacional y transfronteriza y cómo estos informan el auto-conocimiento y la auto-referencia de las personas en relación a lo colectivo, lo familiar, lo personal y a la forma de ubicarse a sí mismos en el mundo. Drummond (1980) afirma que los cambios en una sociedad multiétnica ocurren con las transpolaciones de marcas de identidad, situaciones, prácticas y eventos. Lo más importante es que, en lugar de que el proceso de transpolación se entienda como un rompimiento con la anterior categoría identitaria, étnica o religiosa, las transformaciones deben entenderse bajo la lógica de un continuum cultural. Por otra parte, es importante considerar la multivocalidad de los espacios en los cuales cada individuo proporciona su propio motivo y simbolismo a su localización en el espacio para expresar su identidad (Bowman 1993). En este sentido, ocasionalmente la autodenominación de "clan" o pertenencia regional no tiene ningún significado para los 
habitantes de Tayikistán. Por el contrario, el paisaje local junto con las estrategias para encontrar un lugar donde vivir, y los flujos de ideas y conocimiento informan de una forma más activa las diversas subjetividades y las percepciones individuales y colectivas acerca de la multiculturalidad y la movilidad diaria. Estas teorizaciones cuestionan las nociones de mahalgoroi o regionalismo territorial como fuente principal de las identidades, lealtades y acciones "clánicas" y "culturales". También cuestionan la noción del estado como principal controlador y administrador del espacio físico (Scott 1998).

Reeves (2007) analiza los cambios diarios en la geografía del Valle de Ferghana por medio de la imposición de puestos de control fronterizo que dividen el territorio de Uzbekistán, Kirguistán y Tayikistán; países que, hasta hace unas décadas, eran parte de la URSS. En aquel entonces, los ciudadanos de estos países aparentemente gozaban de libre paso de una república a otra. La autora explora las formas en las cuáles las relaciones familiares, las prácticas cotidianas de comercio y en lo bazares, y las subjetividades individuales y colectivas han sido afectados por la dolorosa experiencia de transportarse de un lado a otro de la frontera al visitar familiares separados por las líneas divisorias oficiales. Por ley, la gente cruzando la frontera necesita de una visa obligatoria, pero la mayoría de las veces nadie posee una. Reeves afirma que para muchos ciudadanos de las "nuevas" repúblicas el colapso de la Unión Soviética ha significado un decremento real en la movilidad, transformando las formas en las cuáles ellos se entienden a sí mismos, a los "otros" (locales y extranjeros) y a la geografía local fronteriza. En Batken, una mujer expresa en relación a Sokh: ${ }^{18}$

“Nosotros íbamos allá al bazaar, a veces solamente para comer. Las chaikhanas [casas de té] eran mucho más civilizadas allá que las nuestras, realmente culturales (kul'turnye), incluso en los tiempos soviéticos". (Reeves 2007:291)

Otro hombre se expresa mientras cruza la frontera tayico-kirguisa:

“...el problema con todos estos controles fronterizos es que los mismos trabajan en nuestro inconciente, comienzan a hacernos reaccionar diferente incluso sin notarlo. Cuando logro cruzar este puesto (uzbeco) sin ningún problema porque soy sokhskii, pero veo que un kirguiso de Tuz-Bel (un pueblo kirguiso al sur de Sokh) es parado y revisado, esto me lanza una señal: "ellos deben de ser peligrosos", comienzo a pensar" (2007:296).

Las experiencias en el cruce fronterizo con sus problemas rutinarios (tales como los retrasos habituales y la corrupción de algunos soldados para conseguir pasar) junto con las percepciones individuales y colectivas acerca del pasado y del presente forman lo que Reeves (2007) denomina "subjetivismo de las fronteras". No obstante, tanto fronteras como límites reales también son experimentados dentro de un mismo país en las ciudades tayicas. Alexander \& Buchli (2007) investigan los cambios en los significados en las previas percepciones y valores de la ciudad socialista, y cómo los nuevos mapas sociales dentro de las ciudades han emergido como áreas que enfatizan las diferencias étnicas y de clase por medio de limitantes de la movilidad y de las posibilidades económicas. Solamente los ricos pueden darse el lujo de vivir en ciertas áreas de la ciudad, mientras otras zonas están habitadas por destituidos y/o migrantes, o son convertidas en enclaves étnicos. Todas estas transformaciones permiten a los ciudadanos pensar no solamente acerca de los espacios urbanos reales y las percepciones imaginadas de fronteras internas gracias a la diferencia de clases, sino también les permite reflexionar acerca de sí mismos y de las nuevas posibilidades dentro de los flujos y cambios en el paisaje. 
Dudoignon (1994) ubica a Dushanbe como la ciudad en la cuál las acusaciones mutuas de "localismo" entre diversos clubes de intelectuales se hicieron actos públicos durante la perestroika y la guerra civil. La autora afirma que en la década de los setentas Dushanbe era vista como el centro de vida intelectual por parte de los estudiantes provenientes de Qarategin y Gharm, quienes veían en ello una buena oportunidad para cambiar el monopolio de poder de los khojandis y samarkandis por medio de la fundación de nuevos clubes culturales y literarios. La autora subraya el proceso conflictivo emergente del encuentro de intelectuales y proyectos provenientes de diferentes regiones. Sin embargo, Marsden (en imprenta) ilustra la complejidad de las relaciones en los centros urbanos que no puede ser resumida en la ecuación propuesta por Dudoignon. Por ejemplo, una familia de pamiris da preferencia a Khojand como sitio en el cuál deciden vivir tras dejar Badakhshan, afirmando que esta zona es más sofisticada y más diversa étnica y lingüísticamente que otras. Con ello, los miembros de la familia no solamente se refieren a la diversidad de la población tayica en el área, sino al importante número de pobladores de origen uzbeco viviendo en la región de Khojand, a quienes la familia percibe incluso como personas más abiertas que otros tayicos. El autor sugiere que la gente en Tayikistán conceptualiza diferentes espacios y ciudades por sus características de socialidad y diversidad, lo cual tiene un impacto directo en las ideas de estética y refinamiento. De esta forma, Dushanbe también es entendida por muchos pamiris, como una ciudad que provee grandes oportunidades para llevar una vida cultural más diversa que en aquellos lugares asociados con un único y dominante grupo "étnico". Marsden (en imprenta) concluye que:

“Aparentemente la disminución de ciertas formas de diversidad étnica y lingüística en lo que alguna vez fueron centros urbanos cosmopolitas simultáneamente tienden a la cristalización de 'nuevas constelaciones de diferencias étnicas y de estatus, las cuales emergen junto con nuevas prácticas urbanas, y requieren la creación de nuevas 'reglas de interacción', utilizadas para negociar y entender formas sociales urbanas emergentes" (Marsden, c.p.).

En la siguiente sección continuaré el análisis de algunas cuestiones relacionadas al espacio y a la movilidad ligadas a temas económicos y que interactúan con la conformación de nuevas subjetividades.

\section{La discusión sobre la "transición" económica: sobre el mercado, el transnacionalismo y las subjetividades}

En el camino de Dushanbe hacia norte del país existe un túnel entre Ayni y la capital que fue planeado como un proyecto de modernización en vista de que la ruta en las montañas (el paso de Anzob) se bloquea en invierno debido a la nieve y a las bajas temperaturas. Ayni es una ciudad importante porque conecta las carreteras de Khojand, Tashkent y Penjikent. Aunque el túnel mencionado está oficialmente en funcionamiento, la mayor parte del tiempo se mantiene cerrado porque tiene fallas estructurales y se inunda constantemente. Mi viaje de Dushanbe hacia Penjikent (270 kilómetros) me tomó cerca de 3 días por las malas condiciones del camino y del atomóvil, así como por el cierre temporal del túnel que me obligó a ir por la ruta montañosa y a pasar un par de noches en un pequeño pueblo a la orilla del camino. Este evento es una propuesta para repensar las relaciones del espacio con los proyectos de modernización (el túnel), los imaginarios de conexión, localidad y transnacionalismo, los problemas económicos y las expectativas en relación a las subjetividades personales y familiares en Tayikistan. Era ya de noche cuando el viejo coche Lada se detuvo nuevamente con el motor sobrecalentado, y Amir decidió que 
pasáramos la noche ahí. De pronto aparecieron unas figuras en la oscuridad. Unas mujeres se aproximaron cautelosamente a nosotros y comenzaron a hablar en tayico, preguntando quiénes éramos y qué queríamos en el kishlak (pueblo). Amir explicó que llevaba a dos chicas extranjeras pero que no podíamos continuar el viaje hacia el norte. Inmediatamente las mujeres nos invitaron a pasar a una casa en el pequeño pueblo de aproximadamente quince casas. Las mujeres prepararon la cena que consistió en pan hecho a mano (nan), cebollas en conserva y crema. La dueña de la casa se disculpó por la falta de carne y huevos y nos explicó las difíciles condiciones en las que vivían. La conversación aquella noche se realizó entre risas y un ambiente relajado mientras las mujeres más jóvenes nos pintaban a mi amiga y a mí una línea negra entre ambas cejas, algo considerado como símbolo de belleza femenina en el lugar. Las mujeres nos hablaron de sus sentimientos y emociones hacia los hombres del pueblo, quienes habían migrado hacia Rusia en busca de trabajo, de los problemas económicos por la magra cantidad de dinero enviada por esposos y hermanos en el extranjero. Ellas se expresaban preocupadas por los problemas morales y de racismo que los tayicos debían enfrentar en Rusia, del inclemente frío en invierno que no permitía el cultivo de frutas o vegetales, y de la incertidumbre acerca del túnel que había dejado al pueblo en una situación "más solitaria que antes". El siguiente día por la mañana mi amiga y yo nos dimos cuenta de que las mujeres tenían pequeños campos de cultivo para el autoconsumo, pero que también producían mermeladas, pepinillos y tabaco seco para vender a la orilla de la carretera. A su vez, nos presentaron a los únicos dos hombres que vivían en el pueblo y que pasaban su tiempo cuidando a unas cuantas cabras. Nuestro día terminó con un par de horas viendo fotografías de las familias y de los hombres migrantes, y escuchando a las mujeres compartir sus sentimientos y ansiedades acerca del presente y del futuro. Una mujer vieja dijo que siempre habían tenido problemas con las bajas temperaturas y con el aparente aislamiento en el invierno, pero que ella personalmente se sentía conectada a otros pueblos cuando veía los cables de la electricidad a lo largo del camino en los viajes que ella y su esposo solían hacer hacia Khojand: "Ahora la gente dice que los rusos son malos, pero ellos trajeron electricidad", concluyó. Cuando mi amiga preguntó si extrañaba a su esposo ella dijo:

“¿Extrañar? ¡Ya nos acostumbramos! Ellos se fueron hace cinco años y raramente se mantienen en contacto. Nuestro pueblo no es el único, en estos tiempos todas las mujeres están igual".

Otra explicaba como preparar los frascos de pepinillos y mermelada, y hasta que punto era importante para ellas vender los productos a la orilla de la carretera. Tristemente expresó:

“Desde que el túnel se inauguró nuestro día no es seguro: no sabemos cuándo se inundará, se cerrará y los carros pasarán por aquí. Cuando los ingenieros verdaderamente resuelvan el problema nos quedaremos aislados."

Una joven de dieciséis años tenía curiosidad de saber cómo mi amiga y yo nos habíamos conocido en Moscú hace algunos años, y preguntaba acerca de la apariencia de las chicas en Moscú. Finalmente dijo preocupada:

"Se ha vuelto muy difícil para mí encontrar marido y casarme porque la mayoría de los hombres del pueblo se van a trabajar a Rusia y casi nunca vuelven".

También afirmaba que ella y otras jóvenes compartían chismes acerca de los hombres tayicos teniendo relaciones inmorales con las "rusas" y "enamorándose" de ellas, e 
incluso viviendo con ellas sin haberse casado y sin tener permiso de los padres. Esta era la causa a la cual ellas atribuían su situación como las chicas solteras del pueblo. Esta joven en particular no sentía que el túnel cambiaría en alguna manera su vida ni tampoco la hacía pensarse más "aislada". Posteriormente todas las mujeres se mostraron emocionadas cuando les ofrecimos enviarles las fotos de ellas y de los niños que habíamos tomado ese día en el pueblo tan pronto como llegáramos a Khojand. Finalmente una expresó:

“Pero por favor ¡No olviden su promesa! Hace dos años dos extranjeros como ustedes llegaron al pueblo...en uno de esos jeeps de...creo que Naciones Unidas.... Compartimos la cena, nos tomaron fotos con ellos y nunca las mandaron ni regresaron!".

Las mujeres en el paso de Anzob nos despidieron preparándonos un desayuno con dos huevos y pan recién horneado.

En la sección previa analicé algunos ejemplos de cómo las subjetividades son pensadas, experimentadas y encarnadas en relación a dos espacios específicos: fronteras y ciudades, siendo la primera una especie de barrera y la última un centro intelectual y "cosmopolita". Ambos se plasmaron como lugares en los cuáles las diferencias económicas y las nuevas oportunidades de experimentar sociedades multiétnicas y multilingüísticas se vuelven reales. Sin embargo, mi discusión acerca de las mujeres en el paso de Anzob demuestra que los pueblos son también centros de conocimiento y de reflexión acerca del espacio, la movilidad y el transnacionalismo, así como de la realidad económica interactuando con la transformación de las diversas subjetividades. En esta sección no intento hacer una distinción binaria sobre las comunidades urbanas y rurales, sino analizar ciertos temas relacionados a cómo los cambios en la economía tienen un impacto en las formas en las cuales la gente experimenta e interactúa con el espacio, con su ubicación en el espacio y con el proyecto modernizador nacional, por medio de la movilidad y de determinadas tendencias transnacionales tales como la migración y la movilidad transregional e internacional, y como estas subjetividades y las estrategias de visibilidad social son conformadas y transformadas en un proceso de movilidad (Osman 2003).

Como ya se mencionó, las tendencias económicas en el mundo post-socialista han sido analizadas por economistas y politólogos en términos de "transición" a la economía de mercado. Sin embargo, Humphrey \& Mandel (2007) subrayan la necesidad de explorar las especificidades de las prácticas locales, las experiencias y respuestas hacia la introducción de actividades capitalistas en aquellos lugares previamente funcionando en una economía socialista de redistribución centralizada. El "mercado", aciertan, no puede ser tomado por hecho como una categoría dada porque sus especificidades se confrontan con la gente en diversos contextos y son experimentadas no solamente como un fenómeno puramente económico ya que:

“Pueden aparecer como un programa de privatización rural, como publicidad sobre cigarros occidentales, como evidencias diarias de crecientes desigualdades entre pobres y nuevos ricos, o como la repentina visibilidad de la prostitución...y la interacción con el mercado capitalista no es una actividad libre de cuestiones morales, sino que se le asigna un valor de acuerdo al contexto político-económico en el cuál opera." (Humphrey \& Mandel 2007: 3,6)

En Tayikistán el mercado capitalista, el estado y la variedad de subjetividades individuales y colectivas también adquieren nuevos significados cuando son ubicadas 
en el contexto del proyecto nacional en relación al cambio en el paisaje (por ejemplo el mencionado túnel), de las tendencias transnacionales (migración de trabajadores), de la ubicación individual y colectiva con respecto al flujo de conocimiento, y de las percepciones estéticas y morales de lo local, lo transnacional y lo global. Los hombres en el extranjero también brindan la oportunidad para reflexionar acerca de la temporalidad y las dislocaciones debido a los lapsos de ausencia y presencia, las implicaciones sobre el cambio de significado sobre aislamiento y desesperación, sobre el papel que juega el amor en el matrimonio, y sobre cómo todos estos cambios finalmente impactan en los nuevos desarrollos y términos de intimidad y vida familiar. Kaneff (2007) afirma que la identidad local puede ser expresada por medio de la participación en la economía de mercado a través de simbolismos adjuntos a las prácticas relacionadas con la comunidad, la familia y aquellos considerados como extraños (o extranjeros). En el caso presentado anteriormente, si hay un proceso de afirmación de la identidad local, el flujo de coches y de gente comprando los tarros de mermelada o pepinillos se convierten en una dimensión de la subjetividad. Rausing (2007) afirma que en Estonia el consumo de productos occidentales, durante algún tiempo conllevó ideas de estatus y percepciones de "normalidad". Aunque no existe evidencia de cómo este proceso es experimentado en Tayikistán, las mujeres que conocí afirmaron que ellas nos invitaron a la casa donde nos quedamos porque recientemente el jefe de familia vino a visitar y trajo algunas cobijas "modernas" y nuevas desde Moscú, lo cual convertía el lugar en un sitio "más apropiado" para las visitas extranjeras.

A pesar de que la migración de trabajadores es una clave importante para entender la transformación de las subjetividades individuales, familiares y colectivas en Tayikistán, esto no significa que sea el único fenómeno relacionado al transnacionalismo. Reeves (2007) se refiere a la "contracción" de la movilidad debido al colapso de la Unión Soviética. No obstante, en otros contextos la movilidad continúa trazando nuevas rutas y especificidades que tienen un impacto en la generación de subjetividades relacionadas a la percepción de una posición económica y no puramente "clánica" o identitaria. Más aún, a continuación analizo cómo la movilidad transnacional y un proyecto internacional liderado por la fundación del Aga Khan propician la regeneración y la centralidad de ciertas subjetividades religiosas en Tayikistán. Marsden (2008) afirma que las prácticas de movilidad dentro Chitral (Nortoeste de Pakistán) son una importante dimensión de la vida cotidiana: con ello el autor cuestiona las suposiciones de que las formas mas significativas de movilidad en el mundo contemporáneo son la global y la transnacional. Él afirma que la movilidad local tiene un efecto visible en cómo los musulmanes se perciben e interactúan con el paisaje, y como este proceso evidencia la complejidad del auto-entendimiento personal y colectivo sobre el ser musulmán. Uno de sus ejemplos relata la historia personal de Sulton, un hombre de Ghorno-Badakhshan (Tayikistán) quien llegó a Chitral en 1999 tras el fin de la guerra civil tayica. El propósito de Sulton era adquirir un mayor conocimiento de la doctrina Isma'ili, pero sintiéndose frustrado tras trabajar en Chitral decide dejar el pueblo. En 2001 Sulton apareció nuevamente, esta vez con una larga barba y vistiendo shalwar kamiz $^{19}$ aunque un año antes normalmente se le veía bien afeitado y vistiendo pantalones al estilo occidental. Sulton iba acompañado por Talibanes afganos quienes desconocían que él era isma'ili porque se hacía pasar por musulmán sunni. Cuatro años más tarde Sulton regresó a Chitral, quejándose de que no podía volver a Tayikistán ni "bajar" a Pakistán porque tenía miedo de ser encarcelado por las fuerzas de seguridad tayicas o por la policía pakistaní, quienes incluso podían enviarlo a Guantánamo. En este caso, la subjetividad religiosa personal funciona en relación al contexto internacional, a los modos reales e imaginarios de percibir las prácticas disciplinarias del estado y a la multivocalidad de lugares y gente habitando las 
multidimensionales fronteras de Tayikistán, Pakistán y Afganistán. Asimismo, enfatiza que los flujos de movilidad tras el colapso del proyecto soviético han ido diversificándose, e interactuado con el desarrollo y la formación de ciertas identidades religiosas y étnicas y con las subjetividades de la gente en Tayikistán, transformando, además, la percepción de su auto-ubicación en el mundo.

No obstante, el proceso de auto-localización en las tendencias transnacionales no es solamente relevante en términos de historias personales. El último ejemplo está ligado al auto-reconocimiento de ser pamiri en relación estrecha con el hecho de que la mayoría de los pamiris son isma'ilis, mientras que el resto de la población de Tayikistán es sunni. La identidad isma'ili ha ganado relevancia y significado en los últimos años gracias a los proyectos y patrocinio de la Red de Desarollo Agha Khan. En Dushanbe por ejemplo, Marsden (en imprenta) percibe una creciente importancia entre las diferencias entre ser sunni y shi'ii ismai'lis como un efecto de la expansión mundial del papel del Agha Khan en la producción de libros y material educativo. Además, la fundación del Agha Khan promueve y otorga a los pamiris un importante número de becas para estudiar en el extranjero, lo cual implica cambios en la identidad religiosa y étnica pamiri en lo que se refiere a la auto-percepción de su centralidad dentro de Tayikistán y en el mundo. Estas oportunidades educativas también les ha concedido, en ciertos aspectos, un estatus diferente en el país como profesionales con títulos académicos internacionales.

Es por ello que las regiones post-soviéticas, y en este caso Tayikistán, no solamente experimentan una contracción y/o expansión del espacio y la movilidad, sino que las oportunidades políticas y económicas para vivir esta movilidad simplemente son diferentes y han adquirido nuevas formas y rumbos. Por una parte, mientras que algunas personas sufren las barreras en los cruces transfronterizos, otros como Sulton, se mueven y experimentan su auto-subjetividad en un continuum físico, religioso y cultural. Por otro lado, mientras que para algunos individuos terminaron los viajes dentro del espacio de la ex-Unión Soviética en lo que era llamado komandirovka, ${ }^{20}$ otros tienen más oportunidades de estudiar y trabajar en el extranjero promovidos por proyectos internacionales tales como los isma'ilis de Badakhshan.

Es necesario agregar que las subjetividades también están infundidas de una variedad de percepciones, practicalidades y emociones sobre las oportunidades económicas reales y las percibidas, así como de los procesos políticos relacionados al "mercado", a la "nación", al "estado", y al "espacio", y son transformadas y constantemente reconformadas por fenómenos locales, nacionales y transnacionales.

\section{Conclusiones}

En este artículo he analizado las limitaciones de "clan" como una categoría de análisis. Mi teoría principal es que las aproximaciones estructuralistas y la naturaleza de los temas que dominan la producción de conocimiento acerca de Asia Central, y específicamente de Tayikistán, han disminuido el valor de las evidencias etnográficas sobre la diversidad y vitalidad de las experiencias humanas en la cotidianidad. Ésto ha restringido durante décadas el análisis de la variedad de formas en las que la gente experimenta e interactúa con las representaciones dominantes y los discursos dentro del estado en el contexto de la vida diaria. A su vez, ha ignorado las formas en las que la gente entiende su cambiante y fluida ubicación en el espacio y en los procesos transnacionales, así como sus diversas características culturales, políticas y religiosas sobre las diferencias y similitudes entre ellos, las cuales contribuyen para la conformación diaria de nuevas formas de socialidad cotidiana. El contraste entre los 
diversos, y frecuentemente paradójicos procesos que toman lugar en la conformación, representación, personificación, interpretación y reflexión de una amplia gama de subjetividades personales y colectivas puede ser más efectivamente analizado si el término "clan" es usado como categoría de análisis tomando en cuenta los discursos, las políticas y las relaciones de poder en el cuál el mismo está contextualizado. Más aún, es importante ubicar cuándo la categoría "clan" se convierte en un término significativo y con sentido en los procesos de la vida cotidiana, cuándo está ausente o no tiene significado para el auto-reconocimiento y hasta que punto ello impacta las diversas formas de subjetividad. Es necesario también repensar si "clan" es una categoría necesaria y útil para referirse a fenómenos concernientes a relaciones clientelares, de poder u otras formas colectivas de auto-representación y socialización.

RM

\section{Bibliografía}

ABASHIN, S. 2006. Post-Soviet nationalism, ethnos, theory, and constructivist critique. Anthropology \& Archaeology of Eurasia 44:4, 58-63.

ABDULLAEV, E. 2002. Central Asian nexus: Islam and politics. In Central Asia: a gathering storm? (ed.) Rumer, B., 245-298. New York: M.E. Sharpe.

ABU-LUGHOD, L. 1989. Zones of theory in the anthropology of the Arab World. Annual Review of Anthropology 18, 267-306.

ADAMS, L. 2007. Public and private celebrations: Uzbekista's national holidays. In Everyday life in Central Asia. Past and Present. (eds) Sahadeo, J. \& Zanca, R., 198212. Bloomington \& Indianapolis: Indiana University Press.

AKBARZADEH, S. 1996. Why did nationalism fail in Tajikistan? Europe-Asia Studies 48: 7, 1105-1129.

ALEXANDER, C. \& V. BUCHLI. 2007. Introduction. In Urban life in post-Soviet Asia (eds) Alexander C., V. Buchli \& C. Humphrey, 1-39. New York: University College London Press.

ANDERSON, B. 1991. Imagined communities: reflections on the origin and spread of nationalism. London: Verso.

ARABOV, O. 2004. A note on Sufism in Tajikistan: what does it look like? Central Asian Survey 23: 3-4, 345-347.

ATKIN, M. 1992. Religious, national and other identities in Central Asia. In Muslims in Central Asia: expressions of identity and change (ed.) Gross, J., 46-72. Durham: Duke University Press.

1994. The politics of polarization in Tajikistan. In Central Asia: its strategic importance and future prospects (ed.) Malik, H., 211-232. Basingstoke: Macmillan.

BAYLY, S. 2007. Asian voices in a postcolonial age: Vietnam, India and beyond. Cambridge: University Press. 
BELOKRENITSKY, V. 2005. Islamic radicalism in Central Asia: the influence of Pakistan and Afghanistan. In Central Asia at the end of the transition (ed.) Rumer, B., 152-191. New York: M.E. Sharpe.

BERGNE, P. 2006. The birth of Tajikistan : national identity and the origins of the Republic. London: I. B. Tauris.

BIEHL, J., B. GOOD \& A. KLEINMAN. 2007. Introduction: rethinking subjectivity. In Subjectivity : ethnographic investigations (eds) Biehl J., B. Good \& A. Kleinman, 1-23. London: University of California Press.

BOURDIEU, P. 1990. The logic of practice. (trans) Nice, R. Cambridge: Polity

Polity

1991. Language and symbolic power. (trans) Raymond, G. Cambridge:

BOTIAKOV, Y. 2003. The institution of violence in Turkmen political culture. Anthropology \& Archaeology of Eurasia 41:4, 45-76.

BOWMAN, G. 1993. Nationalising the sacred: shrines and shifting identities in the Israeli-occupied territories. Man 28-3, 431-60.

BRUBAKER R. \& F. COOPER. 2000. Beyond "Identity". Theory and Society 29:1, 1-47.

CATON, S. 1990. Anthropological theories of Tribe and state formation in the Middle East: ideology and the semiotics of power. In Tribes and State Formation in the Middle East (eds) Khoury P. \& Kostiner J., 74-108. London: I. B. Tauris.

CENTLIVRES P. \& M. CENTLIVRES-DEMONT. 1998.Tajikistan and Afghanistan: the ethnic groups on either side of the border. In Tajikistan: the trials of independence (eds) Djalili, M., F. Grare \& S. Akiner., 3-13. Surrey: Curzon Press.

CERTEAU, M. de. 1984. The practice of everyday life. (tras) Rendall, S. Berkeley \& London: University of California Press.

CHATTERJEE, S. 2002. Politics and society in Tajikistan : in the aftermath of the civil war. Gurgaon, Haryana: Maulana Abul Kalam Azad Institute of Asian Studies.

COLLINS, K. 2006. Clan Politics and regime transition in Central Asia. New York: Cambridge University Press.

DAS, V. 2007. Life and words: violence and the descent into the ordinary. Berkeley: University of California Press.

DAS, V. \& D. POOLE. 2004. The state and its margins: comparative ethnographies. In Anthropology in the margins of the state (eds) Das V. \& D. Poole,3-34. Oxford: James Currey.

DIUK, N. \& A. KARATNYCKY. 1993. New nations rising: the fall of the Soviets and the challenge of independence. New York: J ohn Wiley.

DRESCH P. \& B. HAYKEL. 1995. Stereotypes and political styles: Islamists and Tribesfolk in Yemen. International Journal of Middle East Studies 27:4, 405-431. 
DRUMMOND, L. 1980. The Cultural Continuum: a theory of intersystems. Man 15-2, 352-374.

DUDAREV, K.P. 2001. A Post-Communist authoritarian regime. In Central Asia: political and economic challenges in the post-Soviet era (ed.) Vassiliev, A. 131-155. London: Saqi.

DUDOIGNON, S. 1994. Une segmentation peut en cacher une autre: regionalismes et clivages politico-economiques au Tadjikistan. Cahiers d'études sur la Méditerranée orientale et le monde turco-iranien 18.

EICKELMAN, D. F. 2002. The Middle East and Central Asia: an anthropological approach. $4^{\text {th }}$ edition, New Jersey: Prentice-Hall.

EMADI, H. 2005. Nahzat-e-Nawin: modernization of the Badakshani Isma'ili communities of Afghanistan. Central Asian Survey 24:2, 165-189.

EVANS-PRITCHARD, E.E. 1949. The Sanusi of Cyrenaica. Oxford: Clarendon Press .

1969. The Nuer: a description of the modes of livelihood and political institutions of a Nilotic people. New York \& Oxford: Oxford University Press.

EVANS-PRITCHARD, E.E. \& M. FORTES. 1987 [1940]. Introduction. In African Political Systems (eds) Evans-Pritchard, E.E. \& M. Fortes, 1-23. London: KPI in association with the International African Institute.

FERGUSON, J. 2006. Global shadows: Africa in the neoliberal world order. Durham \& London: Duke University Press.

FOSTER, R. 1991. Making national cultures in the Global Ecumene. Annual Review of Anthropology 20, 235-260.

FOUCAULT, M. 1972. The archaeology of knowledge. (trans) Sheridan Smith, A.M. London: Tavistock Publications.

FREIZER, S. 2005. Neo-liberal and communal civil society in Tajikistan: merging or dividing in the post war period? Central Asian Survey 24:3, 225-243.

GAFARLY, M.S. \& V. F. RASS. 2001. The preservation of the state's dominant positions in the economy. In Central Asia: political and economic challenges in the post-Soviet era (ed.) Vassiliev, A. 100-130. London: Saqi.

GEISS, P. G. 2003. Pre-tsarist and tsarist Central Asia: communal commitment and political order in change. London: Routledge Curzon.

GILSENAN, M. 1990. Very Much Like a Camel: the appearance of an Anthropologist's Middle East. In Localizing Strategies: Regional Traditions of Ethnographic Writing (ed.) Fardon R. 222-239. Edinburgh : Scottish Academic Press. 
GROSS, J. 1992. Approaches to the problem of identity formation. In Muslims in Central Asia: expressions of identity and change (ed.) Gross, J., 1-25. Durham: Duke University Press.

GULLETTE, D. 2007. Theories on Central Asian factionalism: the debate in political science and its wider implications. Central Asian Survey 26:3, 373-387.

GUPTA, A. 1995. Blurred boundaries: the discourse of corruption, the culture of politics, and the imagined state. American Ethnologist 22-2, 375-402.

HANKS, R. 2005. Central Asia: a global studies handbook. Santa Barbara: ABC-CLIO.

HANSEN, T.B. \& F. STEPPUTAT. 2001. Introduction. In States of imagination (eds) Hansen T.B. \& F. Stepputat, 1-37. Durham \& London: Duke University Press.

HERZFELD, M. 1992. The Social Production of Indifference: Exploring the Symbolic Roots of Western Bureaucracy. Chicago: University Press.

HIRSCH, F. 2005. Empire of nations: ethnographic knowledge and the making of the Soviet Union. Ithaca \& London: Cornell University Press.

HOLT RUFFIN, M. 1999. Introduction. In Civil Society in Central Asia (eds) Holt Ruffin, M. \& D. Waugh., 27-33. Seattle: University of Washington Press.

HUMPHREY, C. \& R. MANDEL. 2007. The market in everyday life: ethnographies of Postsocialism. In Markets and moralities : ethnographies of postsocialism (eds) Mandel R. \& C. Humphrey, 3-15. Oxford: Berg.

IBAÑEZ, D. 2007. Introducción al studio de Asia Central. México D.F.: FCPyS-UNAM.

ILKHAMOV, A. 2004. Archaeology of Uzbek identity. Central Asian Survey 23:3-4, 289326.

ILOLIEV, A. 2008. The Ismaili-Sufi Sage of Pamir: Mubarak-i Wakhani and the Esoteric Tradition of the Pamiri Muslims. New York: Cambria Press.

- 2007. Neopatrimonialism, interest groups and patronage networks: the impasses of the governance system in Uzbekistan. Central Asian Survey 26:1, 65-84.

JAHANGIRI, G. 1998. The premises for the construction of a Tajik National identity. In Tajikistan: the trials of independence (eds) Djalili, M., F. Grare \& S. Akiner., 14-41. Surrey: Curzon Press.

JEGANATHAN, P. 2004. Checkpoint; anthropology, identity, and the state. In Anthropology in the margins of the state (eds) Das V. \& D. Poole, 67-80. Oxford: James

Currey.

JENKINS, T. 1994. Fieldwork and the perception of everyday life. Man 29:2, 433-455.

JONSON, L. \& R. ALLISON. 2001. Central Asian security: internal and external dynamics. In Central Asian security : the new international context (eds) Allison R. \& L. J onson., 1-23. London: Royal Institute of International Affairs. 
KAMP, M. 2007. The wedding feast: living the new Uzbek life in the 1930s. In Everyday life in Central Asia. Past and Present. (eds) Sahadeo, J. \& Zanca, R., 103-114. Bloomington \& Indianapolis: Indiana University Press.

KANDIYOTI, D. 1994. Identity and its Discontents: Women and the Nation. In Colonial discourse and Post-colonial theory: a reader (eds) Williams P. \& L. Chrisman.,376-391. Sussex: Harvester.

2002. How far do analyses of postsocialism travel? The case of Central Asia. In Postsocialism: ideals, ideologies, and practices in Eurasia (ed.) Hann, C. M. 238-257. London \& New York: Routledge.

KANEFF, D. 2007. The shame and pride of market activity: morality, identity and trading in Postsocialist rural Bulgaria. In Markets and moralities : ethnographies of postsocialism (eds) Mandel R. \& C. Humphrey, 33-51. Oxford: Berg.

KHALID, A. 2007. Islam after communism: religion and politics in Central Asia. Berkeley \& London: University of California Press.

KOVALSKII, V. F. 2001. Democratic declarations and political realities. In Central Asia: political and economic challenges in the post-Soviet era (ed.) Vassiliev A., 235-251. London: Saqi.

KROSKRITY, P. 2000. Regimenting languages: language ideological perspectives. In Regimes of language: ideologies, polities and identities (ed) Kroskrity, P. 1-34. Oxford: James Currey.

KUZMIN, A. 2001. The causes and lessons of the civil war. In Central Asia: political and economic challenges in the post-Soviet era (ed.) Vassiliev A., 175-219. London: Saqi.

LEDERMAN, R. 1998. Globalization and the future of culture areas: Melanesianist Anthropology in transition. Annual Review of Anthropology 27, 427-449.

LEDENEVA, A. 1998. Russia's economy of favours: blat, networking, and informal exchange. Cambridge: University Press.

MAKHAMOV, M. 1994. Islam and the political development of Tajikistan after 1985. In Central Asia: its strategic importance and future prospects (ed.) Malik, H., 195-210. Basingstoke: Macmillan.

MALASHENKO, A. 2001. Islam in Central Asia. In Central Asian security: the new international context (eds) Allison R. \& L. Jonson., 49-68. London: Royal Institute of International Affairs.

MARKOWITZ, L. 2008. Local elites, procurators and extraction in rural Uzbekistan. Central Asian Survey 27: 1, 1-14.

MARSDEN, M. 2008. Muslim cosmopolitans? Transnational life in Northern Pakistan. The J ournal of Asian Studies 67-1, 213-247. 
(forthcoming). "For Badakhshan - the country without borders!": village cosmopolitans, urban-rural networks and the post-cosmopolitan city in Tajikistan. In The Post-cosmopolitan city (ed) Humphrey, C. (forthcoming)

MEGORAN, N. 2005. Preventing conflict by building civil society: post-development theory and a Central Asian-UK policy success story. Central Asian Survey 24:1, 83-96.

MICHELUTTI, L. 2008. The vernacularisation of democracy: politics, caste and religion in India. New Delhi: Routledge.

NAVARO-YASHIN, Y. 2002. Faces of the state. Secularism and public life in Turkey. Princeton \& Oxford: Princeton University Press.

NAUMKIN, V. 1994. (ed.) Central Asia and Transcaucasia: ethnicity and conflict. Westport: Greenwood Press.

- 2005. Radical Islam in Central Asia: between pen and rifle. Lanham, Md., Oxford: Rowman \& Littlefield.

NOELLE-KARIMI, C. 1997. State and tribe in nineteenth-century Afghanistan : the reign of Amir Dost Muhammad Khan (1826-1863). Richmond \& Surrey: Curzon Press.

NORTHROP, D. 2004. Veiled empire: gender and power in Stalinist Central Asia. Ithaca \& London: Cornell University Press.

NOURZHANOV, K. 2005. Saviours of the nation or robber barons? Warlord politics in Tajikistan. Central Asian Survey 24:2, 109-130.

OLCOTT, M.B. 2005. Central Asia's second chance. Washington, D.C., Bristol: Carnegie Endowment for International Peace, University Presses Marketing.

OSSMAN, S. 2007. Introduction. In Places we share: migration, subjectivity, and global mobility (ed.) Ossman S., 1-16. Plymouth: Lexington Books.

PÉTRIC, B.M. 2002. Pouvoir, don et réseaux en Ouzbékistan post-soviétique. Paris: Presses Universitaires de France.

PETROVA-AVERKIEVA, Y. 1980. Historicism in Soviet ethnographic science. In Soviet and western anthropology (ed.) Gellner E., 19-27. London: Duckworth.

RABINOWIZ, D \& KHAWALDE. 2000. Demilitarised, then dispossessed: the Kirad Bedouins of the Hula Valley in the context of Syrian-Israeli relations. International J ournal of Middle East Studies 32-4, 511-530.

RADNITZ, S. 2005. Networks, localism and mobilization in Aksy, Kyrgyzstan. Central Asian Survey 24:4, 405-424.

RASHID, A. 2002. Jihad: the rise of militant Islam in Central Asia. New Haven: Yale University Press.

RAUSING, S. 2007. Re-constructing the "Normal": identity and the consumption of Western Goods in Estonia. In Markets and moralities : ethnographies of postsocialism (eds) Mandel R. \& C. Humphrey, 127-142. Oxford: Berg. 
REEVES, M. 2007. Travels in the margins of the state: everyday geography in the Ferghana Valley Borderlands. In Everyday life in Central Asia. Past and Present. (eds) Sahadeo, J. \& Zanca, R., 281-300. Bloomington \& Indianapolis: Indiana University Press.

ROULAND, M. 2007. Music across the Kazakh Steppe. In Everyday life in Central Asia. Past and Present. (eds) Sahadeo, J. \& Zanca, R., 213-227. Bloomington \& Indianapolis: Indiana University Press.

ROY, O. 2000. The new Central Asia: the creation of nations. London: I. B. Tauris.

RUMER, B. 2005. Central Asia: at the end of the transition. In Central Asia at the end of the transition (ed.) Rumer, B., 3-67. New York: M.E. Sharpe.

RUMER, E. 2007. The United States and Central Asia: in search of a strategy. In Central Asia : views from Washington, Moscow, and Beijing (eds) Rumer, E., D. Trenin \& H. Zhao., 18-74. New York: M.E. Sharpe, Inc.

SCHATZ, E. 2002. Modern clan politics : the power of 'blood' in Kazakhstan. Seattle: University of Washington Press.

SCOTT, J.C. 1998. Seeing Like a State: How Certain Schemes to Improve the Human Condition Have Failed. New Haven: Yale University Press.

SCHETTER, C., R. GLASSNER \& M. KAROKHAI L. 2007. Beyond Warlordism. The local security architecture in Afghanistan. Internationale Politik and Gesellschaft 2, 136-152.

SHRYOCK, A. 1997. Nationalism \& Genealogical Imagination: Oral and textual authority in Tribal Jordan. Berkeley: University of California Press

SNEATH, D. 2007. The Headless State: aristocratic orders, kinship society, and misrepresentations of nomadic Inner Asia. Columbia University Press.

SOUCEK, S. 2000. A history of inner Asia. Cambridge: University Press.

SPINETTI, F. 2006. Thesis (PhD). Music, politics and identity in Post-Soviet Tajikistan. London: School of Oriental and African Studies, University of London.

SPOLNIKOV, V. 1994. Impact of Afghanistan's War on the former Soviet Republics of Central Asia. In Central Asia: its strategic importance and future prospects (ed.) Malik, H., 95-116. Basingstoke: Macmillan.

STARR, F. 1999. Civil Society in Central Asia. In Civil Society in Central Asia (eds) Holt Ruffin, M. \& D. Waugh., 27-33. Seattle: University of Washington Press.

TREVISANI, T. 2007. After the Kolkhoz: rural elites in competition. Central Asian Survey 26: 1, 85-104.

TRUSHIN, E. \& E. TRUSHIN. 2002. Challenges to economic policy in Central Asia: is a miracle possible? In Central Asia: a gathering storm? (ed.) Rumer, B., 376-428. New York: M.E. Sharpe. 
UYANIK, T. \& C. SEGNI. 2001. Evolution of the banking sector in Central Asia. In Financial transition in Europe and Central Asia: challenges of the new decade (eds) Bokros, L., A. Fleming \& C. Votava., 97-106. Washington D.C.: The International Bank for Reconstruction and Development.

VARISCO, D. 2005. Islam obscured: the rhetoric of anthropological representations. New York: Palgrave Macmillan.

VERKAAIK, O. 2004. Migrants and militants: fun, violence, and Islam in Pakistan. New Jersey: Princeton University Press.

VOLGINA, N. A., M. S. GAFARLY \& N. N. SEMENOVA. 2001. The transition to a modern market economy. In Central Asia: political and economic challenges in the post-Soviet era (ed.) Vassiliev A., 252-269. London: Saqi.

WEGERICH, K. 2006. "A little help from my friend?" Analysis of network links on the meso level in Uzbekistan. Central Asian Survey 25:1-2, 115-128.

WIKTOROWICZ, Q. 2000. Civil Society and social control: state power in Jordan. Comparative Politics 33:1, 43-61.

ZHUKOV, S. 2002. Central Asia: development under conditions of globalization. In Central Asia: a gathering storm? (ed.) Rumer, B., 333-375. New York: M.E. Sharpe.

2005. Kyrgyzstan and Uzbekistan: landlocked agrarian economies with an unlimited supply of labor. In Central Asia at the end of the transition (ed.) Rumer, B., 297-328. New York: M.E. Sharpe.

ZVIAGEL'SKAIA, I. 2005. Russia and Central Asia: problems of security. In Central Asia at the end of the transition (ed.) Rumer, B., 71-92. New York: M.E. Sharpe.

\section{Notas}

\footnotetext{
${ }^{1}$ Este artículo no hubiera sido posible sin el apoyo de mi familia, a la que debo mi estancia en SOAS. Especialmente estoy en deuda con mis padres Refugio Ibáñez y Carmen Tirado. También agradezco al Dr Magnus Marsden por sus significativos comentarios y sugerencias sobre esta investigación. A su vez, recibí el apoyo de los profesores Marilú Sierra Kobeh, Manuel Ruiz Figueroa, Hernán Taboada y Alfredo Romero, así como la ayuda incondicional de Gema Laherran, Zayd Majoka, Momoko Kamata y las mujeres que me abrieron la puerta de sus casas en el paso de Anzob.

${ }^{2}$ La traducción más cercana del ruso al español sería ' Kulobis: vayanse todos a la verga!'.

3 Blat se refiere al uso personal e informal de contactos con el propósito de obtener bienes, favores y servicios atraves de redes clientelares que operan fuera de los procedimientos institucionales formales (Ledeneva 1998).

${ }^{4}$ El discurso antropológico sobre Medio Oriente se ha concentrado en tres zonas teóricas: a) tribus y teoría de la segmentacion b) género, sexualidad y la mujer c) Islam (Abu Lughod 1989).

${ }^{5}$ Natsiia ("nación") fue un termino utilizado por el Partido Comunista (PC) referente a las comunidades sociales evolucionadas históricamente conformadas por diversas tribus y razas, pero unidas por una lengua común, así como por un territorio compartido y una forma de producción económica específica. Narodnost' ("nacionalidad" y/o "nación") fue usado por los etnógrafos rusos para describir a grupos compartiendo una 'escencia cultural' o byt. Los elementos del byt fueron resumidos en lenguage y grupo confesional (Hirsch 2005).

Plemia (traducido como "tribu" y/o "etnia"), describe a grupos endógamos que conforman una confederación de varios rod. Rod, comúnmente es traducido como "clan", y es una unidad exógama en un grado de organización menor a la tribu. De acuerdo a Geiss (2003), los etnógrafos zaristas y soviéticos clasificaron los grupos humanos de forma jerárquica para describir una realidad social desde un punto de vista 'objetivo' (Geiss 2003).
} 
${ }^{6}$ En los últimos años también ha habido una gran producción por parte de autores tayicos referente a los Isma'ilis de la región de Pamir, vease Arabov (2004), Emadi (2005), Iloliev (2008).

7 El libro de Khalid sobre Islam en Asia Central (2007) es una excepción a la literatura enfocada al "radicalismo". Sin embargo, el tema principal sigue siendo la relación histórica entre Islam y política.

8 Foucault (1972) teorizó la "arqueología del conocimiento" como una forma de trazar los orígenesy el desarrollo de las formaciones discursivas, como una metodología que cuestiona las bases sobre las cuales los diversos tipos de conocimiento y teoría se han vuelto posibles.

9 Navaro-Yashin (2002) problematiza la cuestion de la "autenticidad" criticándo los intentos de algunos académicos de encontrar la "escencia" de la "cultura" turca basándose en una distinción entre los puntos de vista nativos y los occidentales. Ella afirma que es imposible encontrar espacios en los cuáles el llamado "Occidente" y la denominada "Turquía" no hayan estado instrínseca e históricamente relacionados.

10 Brubaker \& Cooper (2000) (siguiéndo la teorías de Bourdieu) afirman que las categorías de práctica son categorías de uso cotidiano, expresadas por actores sociales ordinarios. Éstas se distinguen de las categorías de análisis que son experimentadas en el nivel académico por analistas de las ciencias sociales.

${ }^{11}$ Evans-Pritchard y Fortes (1941) desarrollaron teorías acerca de los diversos tipos de sociedades en África enfatizando la carencia de estado como institución. Más aún, Evans-Pritchard elaboró la teoría de la segmentación para explicar ciertos aspectos organizacionales y de funcionamiento de los Nuer en Sudán (1969) y de los Sanusi en la Cirenáica (1949).

12 También se enfatiza la fragmentación de las tribus en grupos más pequeños de acuerdo a su linaje, así como la creación de un sistema de oposición balanceada con ciclos de agresión y mediación.

13 Otros trabajos importates que han contribuído a teorizar tribus y colectividades son: Rabinowitz \& Khawalde (2000), Dresch \& Haykel (1995), Shryock (1997), Wiktorovitz (2000).

${ }_{14}$ Warlordismo es un término basado en un modelo ideal en el cual el estado centralizado mantiene el monopolio del uso de la fuerza en un sentido weberiano. Sin embargo, warlordismo caracteriza a una situación en la cual actores individuales - los llamados warlords o Señores de la Guerra - son identificados como aquellos que, en la práctica, controlan el poder y el uso de la fuerza. (Schetter, Glassner \& Karokhail 2007)

${ }^{15}$ Las citas directas de Marsden (en imprenta) carecen de número de página porque las mismas pueden diferir en el manuscrito que me fué proporcionado en relación con la versión final en proceso de impresión.

${ }_{16}$ Cabe notar que las élites Kulobis son percibidas como las actuales poseedores del poder en el país, mientras que los líderes anteriores provenían de Khojand.

17 De acuerdo a Bordieu (1991), en el "mercado lingüístico" existen percepciones de los productores y de los consumidores de diversos aspectos del discurso. En dicho contexto, ciertos valores de determinadas variantes lingüísticas se convierten en socialmente más valoradas o prestigiosas que otras de acuerdo a las transformaciones en las relaciones sociales de poder.

${ }^{18}$ Batken esta ubicado en Kirguistán y Sokh en Uzbekistán.

${ }^{19}$ Camisa y pantalones sueltos y amplios que generalmente se usan en Pakistán.

${ }^{20}$ El término en ruso se refiere a un viaje de trabajo oficial organizado por el gobierno. Algunas personas en Uzbekistán, especialmente profesionales educados durante el periodo soviético, me expresaron la importancia del komandirovka como una fuente de conocimiento porque representaba la oportunidad para conocer y experimentar más acerca de otros lugares y otra gente. 